\title{
As crianças como objeto de gozo fálico do Outro e o luto patológico
}

Children as object of phallic pleasure of the Other and the pathological mourning

Los niños como objeto de goce fálico del Otro y el duelo patológico

Eduardo S. Sullivan*

\begin{abstract}
Resumo
O mal-estar contemporâneo não deixa de atingir a clínica das crianças, constituindo um campo de ações nas quais as operações de constituição subjetiva são dificultadas. A elisão ou supressão do luto produz efeitos diferentes nas subjetividades. Como expressão dessa situação, analisamos de que forma o luto patológico materno, quando não tem sido subjetivado, produz efeitos na estruturação da criança. Afirmamos que essas condições da rejeição do não inscrito provocam sérias perturbações no devir subjetivo, originando diferentes pontos de interrupção com consequências variadas em cada uma delas. Analisamos neste artigo as crianças situadas como objeto do gozo fálico do Outro, derivado da fantasmática materna e das operações psíquicas que se encontram perturbadas por essa singular situação.
\end{abstract}

Palavras-chave: Gozo fálico do Outro. Luto patológico. Maternidade. Fetichismo.

\begin{abstract}
The contemporary discomfort does not leave out the clinics of children circumscribing a field of actions where the operations of subjective constitution are in difficulty. The elision or suppression of the mourning, produces varied effects on the subjectivities. As an expression of these presentations we analyzed how the paternal mourning, when it has not been subjectively analyzed, produces effects on the structure of the child. We hold that the rejection of what these conditions cause serious disruptions in the subjective evolution originating from different points of interruptions, with varied consequences in each of them. In this paper we especially analyzed the children placed as objects of Phallic Pleasures of the Other, another correlation of phantasmal as maternal and
\end{abstract}

Licenciado en Psicología, profesor adjunto Seminarios de Orientación "Introducción a la Clínica del duelo" y "Duelo e infancia: la constitución del Sujeto y la falta”. Facultad de Psicología. Universidad Nacional de Mar del Plata. E-mail: eduardo.sullivan@speedy.com.ar; sullivan@mdp.edu.ar. 
psychological operations that are disturbed by this particular situation.

Keywords: Phallic pleasures of the Other. Pathological mourning. Motherhood. Fetishism.

\section{Resumen}

El malestar contemporáneo no deja de lado la clínica de niños circunscribiendo un campo de acciones en el que las operaciones de constitución subjetiva se encuentran dificultadas. La elisión o supresión del duelo, produce efectos distintos en las subjetividades. Como expresión de esas presentaciones analizamos cómo el duelo patológico materno, cuando no ha sido subjetivado, produce efectos en la estructuración del niño. Sostenemos que esas condiciones del rechazo de lo no inscripto ocasionan serias perturbaciones en el devenir subjetivo originando diferentes puntos de interrupción, con consecuencias variadas en cada una de ellas. En este trabajo se analiza especialmente a los niños situados como objeto de goce fálico del Otro, como correlato de la fantasmática materna y las operaciones psíquicas que se encuentran perturbadas por esta singular situación.

Palabras clave: Goce fálico del Otro. Duelo patológico. Maternidad. Fetichismo.

Los ojos han ido achicándose desde que él murió $\mathrm{y}$ ahora parecen dos heridas rectas y cortas a medio cicatrizar. Ahora parecen no destellar más que cuando por momentos la certidumbre y no el simple recuerdo de que él murió la arrasan provocándole una desesperación súbita análoga a la locura. Pero ahora parecen no solo no destellar, parecen incluso ciegos y no existir. Juan José Saer, El limonero real. (2008, p. 19).

\section{Introducción}

na de las características distintivas de nuestra época, es el intento de borrar las huellas de la muerte, lo que genera como contrapartida un empuje hacia el goce. La imposibilidad de la elaboración de los duelos es el producto de la promesa capitalista de que nada hará falta. Ariès (1987) y Allouch (2006) demarcan que la experiencia contemporánea de la muerte se encuentra signada por la elisión del duelo y del rito, trayendo 
graves consecuencias para las subjetividades. Si tomamos como referencia lo trabajado por Lacan $(1958 ; 2006)$ respecto a la importancia del rito como marco que permite la inscripción y la subjetivación de la muerte, no podemos dejar de advertir que la caída de las referencias imaginarias y simbólicas en los procesos de la patología del duelo dejan al descubierto el agujero de la existencia que no logra ser bordeado, convocando a la locura y a la violencia. Lo no inscripto se muestra de igual modo de diversas formas. La clínica de las patologías graves de la infancia son una muestra de tales condiciones.

Otra singularidad de este tiempo es el uso y el valor que cobra el objeto niño, donde las fronteras de lo imposible no encuentran tope. Como consecuencia de ello, el infante queda alojado en los cánones del uso fetichístico, esto es, como objeto de goce fálico del Otro. La clínica de niños actual nos acerca a estas realidades circunscribiendo un campo donde las operaciones de constitución subjetiva se encuentran dificultadas. El caso del duelo no elaborado es un ejemplo de la demanda creciente de niños alojados en estas características, como producto de la caída del orden simbólico y la desimplicación de los padres por el padecimiento que portan, buscando su causa por fuera de los significantes que lo representan.

Los procesos de la patología del duelo -sobre todo los vinculados a las relaciones que se entablan entre la falla en la elaboración de un duelo en la madre y las consecuencias para el niño- conforman una vía regia para adentrarse en las particularidades de las razones estructurales del Sujeto y la falta. Estos tropiezos en la constitución permiten el estudio de las relaciones entre perversión y psicosis, enunciados por Freud en Fetichismo (2000) a propósito del fenómeno renegatorio en los duelos no elaborados.

Nuestra experiencia con estos padecimientos nos han permitido contornear algunas de las particularidades con las que se presentan. Por ejemplo: la carencia de pedido de los padres; las modalidades de la transferencia; la falla en las operaciones de inscripción de la falta en el niño y en los fantasmas parentales y la distribución de los goces respecto a la pareja conyugal.

Estas consultas alentadas muchas veces por un tercero (escuela, pediatra, justicia) no responden a la lógica del síntoma, si lo pensamos como una respuesta del lado del Sujeto del deseo. Más bien se trata de la clínica del trastorno en la constitución psíquica, debido a detenciones o ineficacias de la inscripción de las operaciones fundantes del psiquismo. Es importante diferenciar este, de otros espacios de trabajo de la clínica con niños, porque abre interrogaciones nuevas sobre las posibilidades de operar con otras herramientas diferentes a la de la clínica de la neurosis, al tiempo que nos 
incita a reconocer nuestras propias prácticas ya que no siempre responden a los pedidos de la cura tipo.

Este trabajo tiene como objetivo revisar algunas consideraciones sobre los niños como objeto de goce fálico del Otro, como consecuencia de un duelo no elaborado en la madre. Para ello será necesario examinar las particularidades del goce femenino en las circunstancias de la maternidad, como así también precisar las operaciones psíquicas que se entraman entre el niño y la madre como expresión de ese goce incestuoso.

\section{Desarrollo}

\section{La mujer, la madre, las pérdidas}

El sujeto femenino presenta algunas particularidades en su relación con la falta y por ende esta situación la coloca de un modo diferente ante la pérdida de objeto y su posible elaboración. Freud (1998) nos aleccionaba sobre la cercanía entre la melancolía y el amor en cuanto al aplastamiento que el objeto suscita en el sujeto. El caso del duelo femenino es singular respecto a esta circunstancia. La sombra del objeto cae sobre la mujer en el caso de una pérdida amorosa: duelos que atañen al corazón pero que sostienen al ser femenino estructuralmente y que por ello suelen ser arrasadores, cercanos a la melancolía. El duelo de la mujer la relanza a lo perdido por estructura, a esa demanda a la madre imposible de colmar. La mujer queda afectada a ser el falo y desde allí ese duelo la marcará de una manera excepcional. Existe una condición estructural que hace que la fémina quede en mayor medida ligada a la demanda de amor debido a las marcas que le ha dejado la relación preedípica con su madre. El Penisneid la ubica frente a la falta como una demandante, testimonio que evidencia los reiterados reproches que le dirige por haberle negado el pene. Esta relación estragante madre-hija trasunta una desarmonía constitutiva que le impedirá a ambas abrazar la esperanza del complemento, al tiempo que la hija deberá renunciar al hecho de darle un hijo a la madre que permita calmar el encono de su ser privadas (Chatel, 1993).

La maternidad no se transmite como el falo se pasa entre los hombres, por la castración. Como la maternidad no se transmite, es necesario renunciar a recibir directamente de la madre la autorización de dar a luz, [...]. Es preciso hacerlo (Chatel, 1993, p. 78).

Las elaboraciones lacanianas sobre el goce femenino (Lacan, 1991) nos permiten entender que entre la mujer y la madre no existen las mismas 
correspondencias lógicas de goces; hay una discontinuidad estructural que demarca espacios diferenciados. Por un lado, la madre responde al goce fálico a través de un sustituto del pene ecuacionado en el niño y la mujer quedará ligada al No toda, es decir en ser causa de deseo, como así también al goce más allá de la palabra signado por el Significante de la Falta en el Otro. Este plus, le posibilita a la mujer desprenderse por momentos de la palabra y gozar de otra manera no fálica.

La falta de significante que permita nombrar el sexo femenino la acerca también al límite que comporta la inscripción de la muerte en la estructura. Tanto en uno como en otro caso, se trata de la falla del orden simbólico para escriturar la falta real. En otras palabras sexualidad y muerte quedan particularmente vinculadas en el sujeto femenino, haciendo referencia a que esta carencia de significante deja abierta una herida que se reabre ante cada pérdida de amor.

El duelo es una ocasión exclusiva de anudamiento de estas particularidades del ser, ya que esta sensibilidad a la pérdida de amor las hace más cercana al uso del objeto niño para taponar la angustia, cuando amenaza con romper los bordes del espejo. Es decir, que el duelo tentará a la mujer a no redoblar su falta en ser, perdiendo el objeto de goce que le ha proporcionado su condición de madre mientras dura el embarazo y la crianza. Ese "sentirse plena", es un goce que le permite ir más allá de los límites de la castración, condición exclusiva que la diferencia del hombre, ya que éste no posee la facultad que le permita experimentarlo. Esta suspensión momentánea de su deseo como mujer, deberá ser reeditada nuevamente para que pueda producirse la habilitación a la Metáfora Paterna y a la operatoria del Padre real. La renuncia incondicional al pene ecuacionado en el niño, permitirá la transformación del triángulo imaginario, en el cuadrángulo simbólico, mediando el padre, entre la madre, el niño y el falo.

\section{A. El Sujeto del deseo y los duelos constitutivos}

El psicoanálisis entiende al sujeto infantil más allá de su tránsito por una etapa cronológica de la vida. La infancia concierne a los avatares del sujeto en el intento de conquistar su estatuto deseante a través de la inscripción de la falta.

Concebimos entonces, que el infante deberá transitar sucesivos momentos constitutivos de la estructura en donde se recree la falta para que el objeto se construya, dentro del horizonte de la dimensión freudiana que lo entiende como irremediablemente perdido. Esta tarea atraviesa tanto al Sujeto como 
al Otro, incluyendo distintos tiempos de la constitución subjetiva. El ingreso del Sujeto a la estructura simbólica implica una relación gozosa con el Otro; como tal esa escena que deviene de la inscripción de la muerte, debe tener como saldo una resta de su lugar de objeto. La pérdida de un goce debe operar a partir de la introducción de otro orden que lo interdicte.

Los duelos de la infancia nos permiten entender los duelos en la infancia. La muerte puede ser elaborada cuando las tareas del Otro simbólico permiten sostener la estructura ficcional que admita una manera de ser fantasmatizada. El jugar es para el niño una conquista y por medio de ella es posible recrear una escena sobre la escena, que admita la elaboración y la tramitación de la pérdida. Los duelos no inscriptos, debido a las fallas en la subjetivación, arrojan al Sujeto a la imposibilidad del bordeado de la falta en lo real, determinando diferentes consecuencias para la estructuración subjetiva.

\section{B. La madre, la muerte y el duelo}

Como dijimos, el amor maternal es una respuesta a la privación real, es decir que es un modo normal de velar la falta, con un objeto fetiche. Por ello el niño siempre va a entrar a la estructura como un objeto real, recubierto de un brillo agalmático, que en tanto pueda ser metaforizado ingresa a la operatoria de la castración.

Esta perversión normal a la cual denominamos amor maternal tiene el sesgo de la acción decidida de una mujer de demandar al padre un objeto imposible como correlato de su ser privada. Con ello se introduce un costado de locura en esta demanda al poder conseguir ese objeto, que hace ir a las madres más lejos de esta privación obteniendo como resultado la ecuación niño = falo (Laurent, 1999). La metáfora infantil del falo sólo es bien lograda cuando falla en su fin, cuando ofrece una distancia entre la identificación fálica y la significación fálica. Una cosa es quedar identificado al falo, y otra cosa es ser equivalente porque hay una parte que se preserva, que es el no todo del deseo femenino. Cuando se produce la identificación y no la equivalencia el niño quedará ligado de manera especial al fantasma materno, ofreciendo un apoyo a su narcisismo endeble. La madre hará usufructo del niño como instrumento de goce. Desde este punto, podemos entender a la psicosis como correlato de la perversión (Karothy, 2007). Si bien no nos es posible vincular a la mujer con la perversión, estas condiciones de maternidad - en el caso de 
los duelos no inscriptos - nos permiten pensarlos como una situación de excepción donde el goce queda coagulado bajo esta modalidad.

No produce los mismos efectos para el niño quedar dentro de la significación fálica o representar el goce fálico para la madre. Su ingreso a la estructura será por las vías del falo que dará cuenta de que la identificación primaria se encuentra lograda y alcanzará derroteros diferentes si se transmite como significante o si todo el niño se transforma en el instrumento de goce materno. Estas dos posiciones nos otorgan elementos valiosos para entender de qué modo la madre debe operar para que el infante pueda hacerse de una reserva libidinal que le permita relanzarla a la producción lúdica. Entendemos que el duelo materno inclinaría la balanza hacia uno de los lados produciendo fallas en la imagen narcisista y en la capacidad de hacer uso de los objetos pulsionales fantasmaticamente (Amigo, 2003).

\section{El peligro de las madres en duelo}

En la Grecia antigua, las madres en duelo tenían reservadas una serie de restricciones para que el lamento y el llanto no perturbaran el orden social. Estas peculiares limitaciones a las manifestaciones desbordadas de las dolientes eran sostenidas por el Ginecómano, quien era el encargado de restringir y resguardar el orden de las ciudades, a través de los estrictos cumplimientos de las leyes del duelo. De modo que el peligro potencial que encarnaba la presencia de una madre en duelo atentaba con el límite de lo instituido, ya que intentaba hacerse oír a pesar de las restricciones. "Ya en la ciudad arcaica el duelo gimiente es femenino y por ello debe ser excluído" (Loraux, 2004, p. 17). El temor que presentaban las ciudades ante la suspensión del tiempo y la amenaza de lo político, era producto de esa presencia perturbadora del pathos del duelo; por ello se debía garantizar la realización de ciertos ritos y funerales para apartar la fascinación que producía el placer de las mujeres por las lágrimas.

El duelo, arroja pues a la mujer, a quedar ligada a un fin: "Como si desde los orígenes el duelo debiera formar parte de su destino de madre" (Loraux, 2004, p. 50).

La madre que atraviesa una situación de duelo es objeto de una tentación irrefrenable: atrapar en sus fauces al niño que las completa. Ese tapón a su angustia provoca un goce fetichístico que coloca al niño como sustituto para mitigar ese vacío sin nombre que la muerte abre. Como enunciamos, la condición de privación materna queda redoblada 
ante la pérdida de un objeto amoroso, signando esa peculiar situación en donde el objeto simbólico falta. Si no hay quien mantenga abierta su boca, el niño puede ir de la muerte simbólica a la real. Ese desvío de la mirada materna hacia el cauce de su ser mujer, producirá un efecto liberador para él, producto de la mediación del Padre real. Una causa más allá de ese gusto por el cuerpo del bebé dará lugar a las nuevas coordenadas para su deseo que la convierta en el objeto en causa de un hombre, el padre del niño. Para que esto ocurra, ella deberá abstenerse de gozar de ese modo del niño que porta ese semblante.

[...] el padre debe hacer virar hacia su lado el goce del acto sexual fecundante, el tomado de la concepción, hacia el lado del goce femenino disimulado, secreto, oculto por él, de tal modo que el niño no sepa gran cosa, que no haga de ese goce, un "goce de la madre" dirigido a él. [...] De lo contrario, ese goce femenino es goce de madre, por lo tanto incestuoso y criminal, ella está como la llanura: peligrosamente expuesta al viento. Si la madre es una puta, el hijo arriesga la vida (Chatel, 1993, p. 80).

En las circunstancias que nos ocupa, se denota una pertinaz negativa a abandonar esta finalidad ya que no hay espacio para que la causa de deseo la convoque a otra escena, por fuera de esa dialéctica, ni quien interponga otro orden necesario que la reubique alejada de ese éxtasis sufriente. El duelo deviene así patológico, ya que no hay posibilidad de que el trabajo de duelo avance hacia la contingencia de encontrarse con la incógnita que abre el agujero en lo real y por ello se reniega la falta.

\section{El niño fetiche: objeto de goce}

El niño cobra entonces un valor particular para ella, satisfaciendo la demanda de la madre no solo de completar su falta en ser sino también de velar la ausencia del muerto, evitando así que ella se las tenga que ver sola con ese duelo por fuera de la dialéctica construida entre ambos. Un niño ubicado en estas circunstancias queda atrapado, camuflando el agujero que la muerte presenta. Una veladura que le dificultará la entrada en la Metáfora y con ello en la posibilidad del armado de una respuesta del lado del Sujeto del deseo. Esta modalidad renegatoria con la cual la madre, acepta pero a la vez rechaza la muerte de su objeto amado, trae consecuencias decisivas para la futura estructuración psíquica del infante. La frecuente egosintonía que muestra estas presentaciones clínicas abrevan la idea de la cristalización y la dificultad que ocasiona 
poder extraer de allí ese goce enclavado a partir de maniobras terapéuticas adecuadas.

\section{Conclusiones}

Pensamos como una cuestión de época el usufructo que se extrae de la relación gozosa con el niño, ubicado en los cánones del fetiche. Esta manera perversamente orientada de rellenar el agujero que abre la privación del duelo, produce efectos en las operaciones de constitución subjetiva del infante, deteniendo en la mayoría de las veces la posibilidad del ingreso a la Metáfora Paterna y con ello a buscar otro sentido a la incógnita por el deseo del Otro. La ineficacia de las operaciones de corte que habiliten al niño a crear una respuesta al modo del síntoma, en ocasiones pueden ser conmovidas a partir de la intervención analítica ofreciendo la oportunidad de que el goce pueda ser extraído de esa relación incestuosa con la madre.

La locura de la maternidad conmueve especialmente a la mujer en duelo. Ese destino estructural en anhelar la promesa de falo a partir de su condición de ser privada la tienta hasta el exceso. Y desde allí sus fauces mortificantes retienen al objeto niño dejándolo sin chance para que la complete, pero no toda, de modo que sea posible un deseo mas allá de él. Esta separación fecunda entre el niño y el falo permite la introducción de una hiancia para que se respire cierto aire pulsional y la madre habilite la introducción de la metáfora. En cambio si esto no logra efectuarse, es a raíz del alto valor erótico que el niño cobra para ella como reaseguro que le permita, evitar la pérdida del objeto amado. El duelo queda así congelado, tiñendo de sombría desazón esta relación entre el Sujeto y el Otro.

En suma:

a) Si el niño ha logrado la significación fálica es a condición de que la madre lo ha eximido de colmar permanentemente su falta, lo ubica más allá de la correspondencia entre la falta de objeto y la sutura narcisista para ella.

b) Como consecuencia habrá disponible para el niño un objeto para la actividad lúdica, que surgirá de ese recorte del objeto caído a cuenta de su propia reserva libidinal. Si la madre puede faltarle al niño, lo introducirá en sus juegos de presencia - ausencia conformándose en Fort-Da para él. 
c) En cambio, si es el niño quien sostiene a la madre, ella es la que va a hacer de él su muñeca erótica quedando identificado a la satisfacción incesante o al aquietamiento de su angustia. Cuanto más la colma, más la angustia. Así devendrá objeto del goce fálico del Otro. El niño quedará como rehén eterno, legitimando el narcisismo de la madre.

d) Habrá un desfasaje entre la demanda materna y la posibilidad de respuesta del niño, que quedará siempre por fuera de la imagen ideal, y al que no hay espejo donde reconocerse.

e) El objeto (a) no se desprende y por tanto no hay posibilidad de que el niño lo use con fines de juego.

f) El par presencia - ausencia no alterna y el niño no puede faltarle a la madre bajo ninguna circunstancia, porque ello amenaza con desmoronar su subjetividad. Esta existencia de esclavo, le devolverá su lugar de objeto para el Otro, quedando cerrada la posibilidad de incluir a los semejantes y el goce sublimatorio.

\section{Referências}

Allouch, J. (2006). Erótica del duelo en tiempos de la muerte seca. Buenos Aires: El Cuenco de Plata. (Texto original publicado en 1998.)

Amigo, S. (2003). Paradojas clínicas de la vida y la muerte. Buenos Aires: Homo Sapiens.

Ariès, P. (1987). El hombre ante la muerte. Madrid: Taurus Humanidades. (Texto original publicado en 1983.)

Chatel, M. (1993). A falta de estrago una locura de la publicación. Revue du Litoral, 37, 45-83.

Freud, S. (1998). La feminidad. 33a Conferencia de introducción al psicoanálisis. In S. Freud. Obras completas (José Luis Etcheverry, Trad., Vol. 22, pp. 104125). Buenos Aires: Amorrortu Editores. (Texto original publicado en 1932.)

Freud, S. (2000). Fetichismo. In S. Freud. Obras completas (José Luis Etcheverry, Trad., Vol. 21, pp. 147-152). Buenos Aires: Amorrortu Editores. (Texto original publicado en 1927.) 
Karothy, R. (2007). Seminario Complejo de Edipo y Complejo de Castración. Maestría en Psicoanálisis, Facultad de Psicología, UNMdP. Mar del Plata: Comunicación personal.

Lacan, J. (1958). (EFBA) Seminario VI. El deseo y su interpretación. Buenos Aires. Inédito.

Lacan, J. (1991). Seminario XX: Aún. (pp. 95-108). Buenos Aires: Paidós. (Trabajo original publicado en 1972.)

Lacan, J. (2006). Seminario X: La angustia. (pp. 351-365). Buenos Aires: Paidós. (Trabajo original publicado en 1962.)

Laurent, E. (1999). Psicoanálisis con niños y sexualidad femenina. In E. Laurent. Hay un fin de análisis para los niños. (pp. 167-182). Buenos Aires: Diva

Loraux, N. (2004). Madres en duelo. Barcelona: Abada. (Trabajo original publicado en 1990.)

Saer, J. (2008). El limonero real. Buenos Aires: Seix Barral. (Trabajo original publicado en 1974.) 